\title{
Effect of simultaneous shade and drought stress on morphology, leaf gas exchange, and yield parameters of different soybean cultivars
}

\author{
I. SHAFIQ ${ }^{* * *}$, S. HUSSAIN ${ }^{*, * *}$, B. HASSAN ${ }^{* * *}$, M. SHOAIB, M. MUMTAZ ${ }^{*}$, B. WANG ${ }^{* * *}$, \\ A. RAZA ${ }^{*, * *}$, A. MANAF ${ }^{\# \#, ~ M . ~ A N S A R ~}{ }^{\# \#, ~ W . ~ Y A N G ~}{ }^{* * *}$, and F. YANG ${ }^{* * *,+}$ \\ College of Agronomy, Sichuan Agricultural University, 211-Huimin Road, Wenjiang District, 611130 Chengdu, \\ China* \\ Sichuan Engineering Research Centre for Crop Strip Intercropping System, Key Laboratory of Crop Ecophysiology \\ and Farming System in Southwest China (Ministry of Agriculture), Sichuan Agricultural University, Chengdu, \\ China $^{* *}$ \\ Rice Research Institute and Key Laboratory for Major Crop Diseases, Sichuan Agricultural University at Wenjiang, \\ Chengdu, China ${ }^{* * *}$ \\ College of Resources, Sichuan Agricultural University, 611130 Chengdu, China \\ Department of Agronomy, Pir Mehr Ali Shah Arid Agriculture University, Rawalpindi, Punjab, Pakistan ${ }^{\# \#}$
}

\begin{abstract}
An interactive effect of simultaneous shade and drought stress on drought-tolerant and drought-sensitive cultivars of soybean was studied. As drought stress intensified, the net photosynthetic rate decreased in both cultivars due to reduced leaf area, relative water content, transpiration rate, stomatal conductance, chlorophyll content, and Rubisco activity which ultimately led to yield reduction. Moreover, the chlorophyll fluorescence parameters also decreased. Interestingly, a moderate shade was found helpful in alleviating the adverse effects of drought stress, specifically in resistant cultivar N12 where seed yield improved significantly under moderate drought conditions in contrast to the cultivar C103. In summary, the effect of drought stress on soybean depended on the irradiance conditions and shade could enhance soybean drought resistance, although this resistance was cultivar dependent. With appropriate cultivar selection, a moderate shade can help optimize yield and improve the performance of drought-exposed soybean.
\end{abstract}

Keywords: drought; intercropping; morphology; photosynthesis; shade; stress.

\section{Introduction}

One of the major social, economic, and scientific challenges of the modern era is the substantial increase of the human population (Tyczewska et al. 2018). Unfortunately, the current food production levels are not sufficient to fulfill the needs of such a large population. This scenario demands urgent consideration and adequate response to prevent devastating ripple effects. Agricultural practices such as intercropping help maximize resource use and lead to higher yield production on a given piece of land (Raza et al. 2019). Maize-soybean intercropping system is one of the main examples of cereal-legume intercropping (Hussain et al. 2019a). Specifically, maize-soybean relay intercropping is practiced largely in southwestern parts of China (Yang et al. 2018). The system helps in efficient utilization of farmland resources, results in low incidences of diseases, pests, and weeds, improves soil fertility, and results in higher yield and economic benefits.

Soybean [Glycine $\max$ (L.) Merr.], a $\mathrm{C}_{3}$ legume, is an important oilseed crop with over 300 million tons of production globally (Sugiyama 2019). It is being produced and consumed for its protein and oil content (Song et al. 2016). When intercropped with maize, the crop suffers from various abiotic stresses, the most important being the shade stress (Feng et al. 2019, Hussain et al. 2020a) and moisture stress due to adjacent high stalked maize plants (Rahman et al. 2017, Iqbal et al. 2019). A combination of shade and moisture stress leads to biochemical, physiological, and structural changes at the leaf and whole plant level (Holmgren 2000, Sack and Grubb 2002, Sack 2004, Aranda et al. 2005).

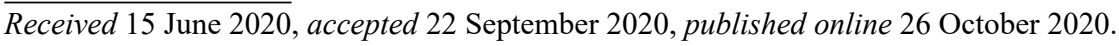

${ }^{+}$Corresponding author; e-mail: f.yang@sicau.edu.cn

Abbreviations: DM - dry mass; $E$ - transpiration rate; ETR - electron transport rate; $\mathrm{F}_{0}$ - minimal fluorescence yield of the darkadapted state; $F M$ - fresh mass; $F_{m}$ - maximal fluorescence yield of the dark-adapted state; $F_{v} / F_{m}-$ maximal quantum yield of PSII photochemistry; $g_{\mathrm{s}}-$ stomatal conductance; $P_{\mathrm{N}}$ - net photosynthetic rate; $\mathrm{q}_{\mathrm{P}}$ - photochemical quenching coefficient; RA - Rubisco activity; RWC - relative water content; TM - turgid mass; $\Phi_{\text {PSII }}$ - effective quantum yield of PSII.

Acknowledgments: The research was supported by the International S \& T Cooperation Projects of Sichuan Province (2020YFH0126) and the Program on Industrial Technology System of National Soybean (CARS-04-PS19).

Conflict of interest: The authors declare that they have no conflict of interest.
} 
Numerous previous studies have reported the negative effect of shade stress on soybean photosynthesis by blocking electron transport from PSII to PSI, thus reducing the electron transport rate, reducing the amount of ATP produced, and the amount or activity of Rubisco (Valladares and Niinemets 2008, Yao et al. 2017, Huang et al. 2018). Similarly, drought stress is also known to disrupt the process of photosynthesis mainly by altering the ultrastructure of the organelles, stomatal regulation, and concentration of various pigments and metabolites including enzymes involved in this process (Ashraf and Harris 2013). Moreover, it inhibits the photosynthesis by decreasing leaf area, photosynthetic rate per unit leaf area as well as Rubisco activity (Galmés et al. 2011, Basu et al. 2016).

Chlorophyll (Chl) fluorescence is one of the main indicators of photosynthetic regulation and plant responses to environmental conditions (Dai et al. 2009, Komura et al. 2010, Murchie and Lawson 2013). Fluorescence emission can be successfully used to monitor photosynthesis disturbances under stress conditions (Zivcak et al. 2014). Earlier studies have highlighted the response of Chl fluorescence to shade and drought conditions in different crops (Hussain et al. 2019b, Zhou et al. 2019, Shafiq et al. 2020). The decrease in Chl content is a commonly observed phenomenon under moisture (Ommen et al. 1999, Manivannan et al. 2007) and shade stress (Zhu et al. 2017) which is also a typical symptom of oxidative stress. In contrast, other researchers report enhanced Chl production in response to lower PAR (Terashima et al. 2006, Gregoriou et al. 2007, Lichtenthaler et al. 2007, Melgar et al. 2009) and water deficit (Estill et al. 1991, Hamada and Al-Hakimi 2001, Pirzad et al. 2011).

Drought and shade stress are important environmental factors in determining the biological yield as they affect plant productivity. Various earlier published literature provides an insight into the effect of shade and drought stress separately on soybean yield (Liu et al. 2003, Karam et al. 2005, Masoumi et al. 2011, Yang et al. 2014, 2017; Iqbal et al. 2018). Although great research effort has been made towards understanding the effects of shade and drought stress on soybean productivity, little attention has been given to the combined effect of both abiotic stresses. An understanding of how soybean plants respond to a combination of moisture and shade stress can play a principal role in stabilizing crop performance under stress conditions. Therefore, the present research was aimed to evaluate the interactive effect of drought and shade stress on growth, photosynthetic parameters, Rubisco activity, and yield components of the two soybean cultivars.

\section{Materials and methods}

Plant material and growth conditions: A pot experiment was conducted in 2019 in a greenhouse at the Sichuan Agricultural University, Chengdu campus, China. Seeds of two soybean genotypes, Nandou-12 (N12; shade- and drought-resistant) bred by NAAS (Nanchong Academy of Agricultural Sciences) and C-103 (C103; shade- and drought-susceptible), were used. The plants were grown in the containers (internal diameter of $17.5 \mathrm{~cm}$ and $17.5 \mathrm{~cm}$ high) filled with a mixture of soil, sand, and organic matter $(5: 3: 2, \mathrm{v} / \mathrm{v} / \mathrm{v})$. The soil was taken from the Renshou experimental area. At the start of the study, the soil $\mathrm{pH}$ (1:2.5, soil:water) was 6.8 ; soil contained $20.5 \mathrm{~g}$ (organic matter) $\mathrm{kg}^{-1}, 1.5 \mathrm{~g}$ (total $\left.\mathrm{N}\right) \mathrm{kg}^{-1}, 110 \mathrm{mg}$ (available $\left.\mathrm{N}\right) \mathrm{kg}^{-1}$, $12.6 \mathrm{mg}\left(\right.$ Olsen-P) $\mathrm{kg}^{-1}, 115 \mathrm{mg}($ exchangeable $\mathrm{K}) \mathrm{kg}^{-1}$, and cation exchange capacity of $22.1 \mathrm{cmol}_{\mathrm{c}} \mathrm{kg}^{-1}$ of dry soil in the top $20-\mathrm{cm}$ soil layer. The experiment was designed as a CRD (completely randomized design) experiment with three factors, i.e., two cultivars, two light regimes, and three drought treatments. There were 12 treatments in total, each treatment had further three replications and five pots per replication were used.

Experimental scheme: The plants of both the cultivars were grown under two different light environments, i.e., full light (L; PPFD = 1,000-1,200 $\mu \mathrm{mol} \mathrm{m} \mathrm{m}^{-2} \mathrm{~s}^{-1}$ at noon) and a moderate shade $(\mathrm{S}$; using single-layer black nylon net with PPFD $=500-600 \mu \mathrm{mol} \mathrm{m}^{-2} \mathrm{~s}^{-1}$ at noon) throughout the vegetative growth period. When plants grown in each light environment reached the V2 stage (the vegetative stage with second fully developed trifoliate leaves), they were divided into three groups; one group was watered regularly to maintain $75 \pm 2 \%$ field capacity ( $\mathrm{T} 1$; control) while water for remaining two groups of plants was withheld up till the V5 stage (the vegetative stage with fifth fully developed trifoliate leaves) to maintain drought conditions, i.e., moderate drought (T2;55 $\pm 2 \%$ field capacity) and severe drought (T3; $35 \pm 2 \%$ field capacity). The drought levels were maintained on a mass basis, i.e., gravimetrically. Moreover, the drought level in the substrate was maintained similar under both light regimes. As the reduction of water content under shade conditions was lesser, the pots were watered accordingly, whereas water loss in the pots under full light was comparatively larger, thus, more frequent watering was required to maintain the desired moisture content during the drought treatments. The data for various morphological and physiological traits were recorded at the V5 stage. At beginning of the R1 stage (the beginning of flowering), shade from all plants was removed (i.e., no shade during the reproductive growth period which imitates the light conditions in the maize-soybean relay intercropping system) and all plants were watered regularly to maintain $75 \pm 2 \%$ field capacity. Finally, yield data were recorded at the R7 stage (the reproductive stage with mature pods).

Morphological parameters: At the V5 stage, plants from each treatment were destructively sampled to measure various morphological parameters. The plant height $[\mathrm{cm}]$ was measured using a scale. Then plants were divided into different parts: roots, stem, leaves, and petioles. The fresh mass was recorded using an electronic balance. Then plant parts were exposed to $105^{\circ} \mathrm{C}$ for $1 \mathrm{~h}$ and dried to constant mass at $75^{\circ} \mathrm{C}$ to determine the biomass.

Chlorophyll (Chl) content and leaf relative water content: The Chl content was measured in samples from three latest fully expanded trifoliate leaves at the V5 stage 
from each treatment using SPAD 502 (Minolta, Japan). For relative water content, three most recently expanded trifoliate leaves from each treatment were destructively sampled and their fresh mass was recorded. Fresh leaf samples were kept in $100 \mathrm{ml}$ of distilled water for a period of $24 \mathrm{~h}$ and then their turgid mass was recorded. Subsequently, the leaves were dried in an oven at $70^{\circ} \mathrm{C}$ for $48 \mathrm{~h}$ and their dry mass was recorded. Relative water content (RWC) was determined using the following formula (Faijunnahar et al. 2017): RWC $=[(\mathrm{FM}-\mathrm{DM}) /$ $(\mathrm{TM}-\mathrm{DM})] \times 100$, where $\mathrm{FM}=$ fresh mass; $\mathrm{DM}=$ dry mass; $\mathrm{TM}=$ turgid mass.

Leaf gas-exchange parameters: Three fully expanded trifoliate leaves of soybean plants at the V5 stage from each treatment were selected and their photosynthetic characteristics [net photosynthetic rate $\left(P_{\mathrm{N}}\right)$, stomatal conductance $\left(g_{\mathrm{s}}\right)$, and transpiration rate $\left.(E)\right]$ were measured using a $L i-6400$ portable photosynthesis system ( $L I-C O R$ Inc., Lincoln, NE, USA) under steady light intensity from 09:00-11:00 h. The equipment settings used were: $\mathrm{PAR}=1,000 \mu \mathrm{mol}($ photon $) \mathrm{m}^{-2} \mathrm{~s}^{-1}$, stomatal ratio $=0.5$, flow $=500 \mu \mathrm{mol} \mathrm{mol}^{-1}$, and reference $\mathrm{CO}_{2}$ concentration $=$ $400 \mu \mathrm{mol} \mathrm{mol}{ }^{-1}$. The aperture size of the instrument was $6 \mathrm{~cm}^{2}$ and the leaf temperature was $26^{\circ} \mathrm{C}$.

Chl fluorescence: A previously published method was followed by using FluorImager software (Technologica, version 2.2.2.2) (Hussain et al. 2019b). Three latest fully expanded trifoliate leaf samples from each treatment were taken at the V5 stage and immediately preserved in plastic bags and placed in an icebox to prevent direct light. Then, by using the above-mentioned software, samples were passed through the fluorescence analyzing device. Images of the minimum Chl fluorescence yield $\left(\mathrm{F}_{0}\right)$ in the dark-adapted state were captured using low-frequency light pulses $(1 \mathrm{~Hz})$. The maximum fluorescence $\left(\mathrm{F}_{\mathrm{m}}\right)$ was determined by applying a blue saturation pulse $(10 \mathrm{~Hz})$. The maximum quantum yield of the PSII photochemistry $\left(\mathrm{F}_{\mathrm{v}} / \mathrm{F}_{\mathrm{m}}\right.$ ratio) was determined, and images were captured. Actinic illumination $\left[1,000 \mu \mathrm{mol}\right.$ (photon) $\left.\mathrm{m}^{-2} \mathrm{~s}^{-1}\right]$ was the same for all the samples. Photochemical efficiency of PSII, photochemical quenching $\left(\mathrm{q}_{\mathrm{P}}\right)$, and electron transport rate $\left[\mathrm{ETR} ; \mathrm{ETR}=\Phi_{\mathrm{PSII}} \times \mathrm{PAR} \times 0.5 \times \alpha\right.$, where $\mathrm{PAR}=1,000$; $\alpha=0.85]$ were examined by placing leaves for $20 \mathrm{~min}$ under light and dark conditions.

Rubisco activated enzyme: To determine the Rubisco activated enzyme, a previously described method was used (Hussain et al. 2019b). The Rubisco ELISA kit (96 micropores) was purchased from Shanghai Fu Life Industry Co., Ltd. (Shanghai, China). The double antibody sandwich method was used to determine the content of plant Rubisco activase. One g of frozen leaf samples of each treatment was ground using $2 \mathrm{ml}$ of $50 \mathrm{mmol} \mathrm{L}^{-1}$ phosphate buffer solution ( $\mathrm{pH} 7.8$ ) with the help of mortar and pestle in an icebox. The homogenate was then centrifuged at $4^{\circ} \mathrm{C}$ for $15 \mathrm{~min}$ at 7,000 rcf, the micropore plate encapsulated the Rubisco activase antibody to form a solid phase antibody. This was added to the micropore of the monoclonal antibody. Then a phosphate buffer solution $(40 \mu \mathrm{l})$ was added first as a buffer solution in the micropore plate, then $10 \mathrm{ml}$ of sample solution was added. The micropore plate was then sealed by a plastic film and incubated at $37^{\circ} \mathrm{C}$ for $30 \mathrm{~min}$. The incubation was repeated over five times. The 3,3'5,5'-tetramethylbenzidine was transferred under the catalysis of the horseradish peroxidase enzyme, which first turned blue and finally to a yellow color under the action of an acid. The stop solution was added, and absorbance was measured within $15 \mathrm{~min}$ at $450 \mathrm{~nm}$ by an enzyme marker. Then, a standard curve was drawn and Rubisco activity was expressed as $\mathrm{U} \mathrm{g}^{-1}$.

Yield component analysis: To evaluate the impact of drought and shade stress on the yield of tested plants, seeds were harvested manually for both cultivars at the maturity stage and then air-dried. Yield components, such as seed yield per plant [g], 100-seed mass [g], the number of grains per plant, the number of pods per plant, and the number of infertile pods per plant, were determined.

Statistical analysis: Factorial analysis of variance $(A N O V A)$ test was performed to test the effect of different drought treatments on the parameters of soybean under a shade and normal light using the Statistix 8.1 software. A significant difference between treatment means was evaluated using Duncan's multiple range test $(p<0.05)$.

\section{Results}

Morphological parameters: Fig. 1 shows the effect of shade and drought stress on soybean morphological parameters at the V5 stage. Shade significantly increased the plant height in both cultivars, the maximum height $(96 \mathrm{~cm})$ was observed in $\mathrm{T} 1$ treatment for $\mathrm{C} 103$ while the minimum value $(31 \mathrm{~cm})$ was recorded in T3 treatment for N12. The plant height decreased significantly as the drought level intensified. The stem, root, petiole, and leaf mass also decreased significantly under shade conditions in comparison to full light for both the cultivars, while the decrease was greater in C103 in comparison to N12. Similarly, the fresh mass for different plant parts decreased with the increasing severity of drought stress. The maximum values for the stem, root, petiole, and leaf mass (4.12, $5.49,1.96$, and $6.39 \mathrm{~g}$, respectively) were recorded for $\mathrm{T} 1$ in N12 under full light while minimum values $(0.93,0.93$, 0.56 , and $1.96 \mathrm{~g}$, respectively) were recorded for $\mathrm{T} 3$ in C103 under shade conditions.

Leaf area and relative water content: Leaf area declined significantly with increasing levels of drought stress under both light regimes in both cultivars. However, in comparison to full light, leaf area decreased significantly (by $10.9,8.9$, and $7.6 \%$ and by $11.6,9.0$, and $18.1 \%$ in $\mathrm{T} 1$, $\mathrm{T} 2$, and $\mathrm{T} 3$ in $\mathrm{N} 12$ and $\mathrm{C} 103$, respectively) under shade environment for all moisture treatments in both cultivars. The maximum value $\left(43.09 \mathrm{~cm}^{2}\right)$ for the leaf area was recorded in T1 in N12 under full light while the minimum value $\left(20.95 \mathrm{~cm}^{2}\right)$ was recorded in T3 in C103 under shade conditions. The interaction of the light environment and moisture treatments was found significant. Decreasing 


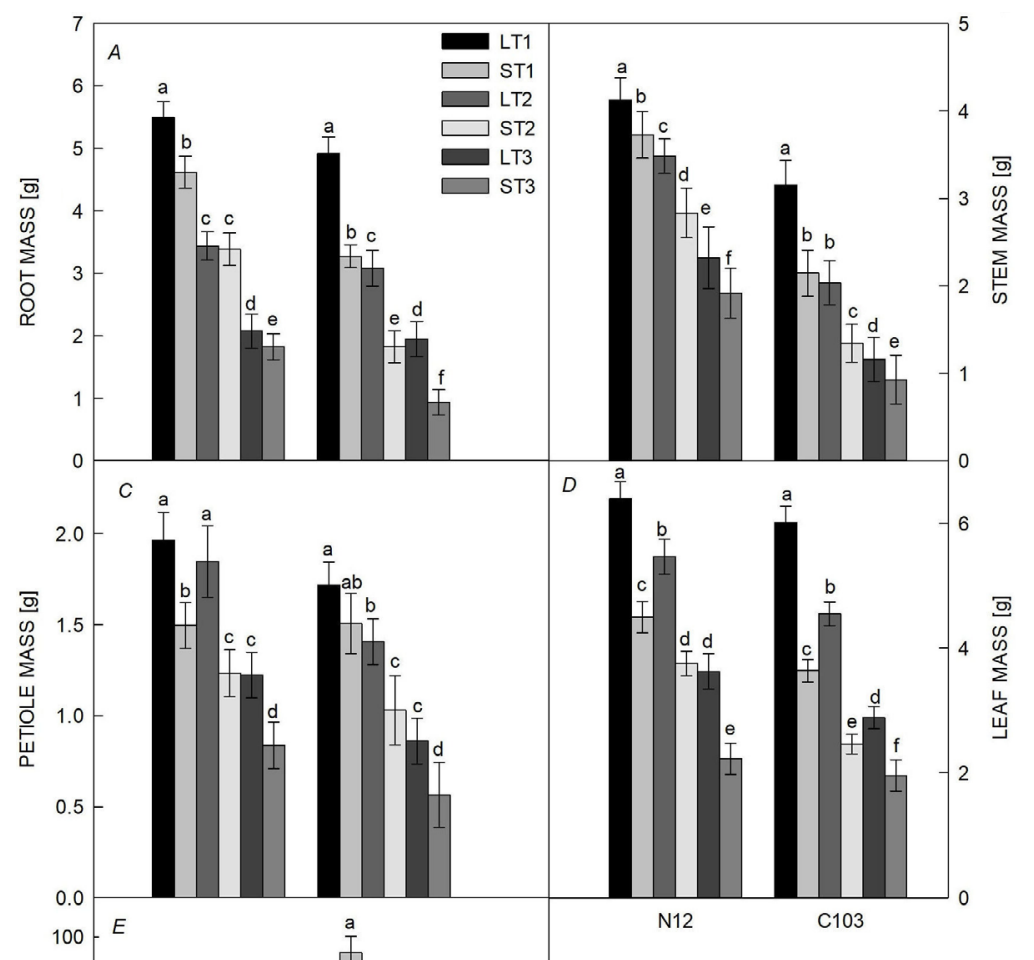

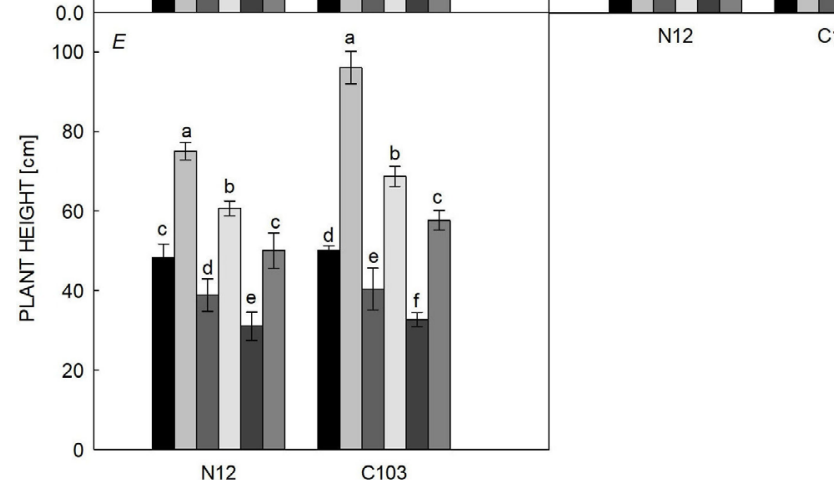

soil moisture content also led to a significant reduction in relative water content (RWC) under both light regimes in both cultivars. The overall RWC was significantly higher under shade conditions as compared to full light for both cultivars (Fig. 2) with maximum (76.6\%) and minimum $(63.0 \%)$ values noticed in $\mathrm{T} 1$ for $\mathrm{N} 12$ under shade environment and T3 in $\mathrm{C} 103$ under full light, respectively. The results suggested that the shade conditions helped in mitigating the drastic effects of drought stress in both soybean cultivars.

Leaf gas-exchange parameters and SPAD value: The leaf gas-exchange parameters and SPAD values were also highly influenced by drought stress under both light regimes in both soybean cultivars (Fig. 3). Increasing the severity of drought stress significantly decreased the photosynthetic rate $\left(P_{\mathrm{N}}\right)$, transpiration rate $(E)$, stomatal conductance $\left(g_{\mathrm{s}}\right)$, and SPAD value in the two cultivars, the decrease was greater in $\mathrm{C} 103$ in comparison to N12. The shade conditions, however, helped ameliorate the negative effects of drought stress in both cultivars. $P_{\mathrm{N}}$ increased significantly in $\mathrm{T} 2$ and $\mathrm{T} 3$ by 16 and $21.3 \%$ in N12 and C103, respectively, under shade conditions
Fig. 1. The effect of different light regimes and drought stress treatments on $(A)$ root mass, $(B)$ stem mass, $(C)$ petiole mass, $(D)$ leaf mass, and $(E)$ plant height of two soybean cultivars, N12 (shade- and drought-resistant) and $\mathrm{C} 103$ (shade- and droughtsusceptible), respectively. L and S refer to full light and shade, respectively. $\mathrm{T} 1, \mathrm{~T} 2$, and $\mathrm{T} 3$ refer to $75 \pm 2 \%$ field capacity (control), $55 \pm 2 \%$ field capacity (moderate drought), and $35 \pm 2 \%$ field capacity (severe drought), respectively. Values are the mean of three replicates. Bars indicate \pm SD. Different lowercase letters above the bars represent a significant difference $(P<0.05)$ between treatments.

in comparison to full light. Initially, the $E, g_{\text {s }}$, and SPAD value in $\mathrm{T} 1$ under shade conditions decreased significantly by $11.1,7.6,7.5$, and $15.6,15.7,7.3 \%$ in N12 and C103, respectively, but a significant increase was observed in $E$ $(15.6$ and $16.8 \%)$ and $g_{s}(18.5$ and $67.6 \%)$ for $\mathrm{T} 2$ and $\mathrm{T} 3$ in N12, respectively. Similarly, $E(16.8 \%)$ and $g_{\mathrm{s}}(138.8 \%)$ improved significantly for $\mathrm{T} 3$ in $\mathrm{C} 103$, respectively. The SPAD value also improved significantly for T2 $(4.7 \%)$ in $\mathrm{N} 12$ and $\mathrm{T} 3(8.2 \%)$ in $\mathrm{C} 103$, respectively. The maximum values for $P_{\mathrm{N}}\left[12.76 \mu \mathrm{mol}\left(\mathrm{CO}_{2}\right) \mathrm{m}^{-2} \mathrm{~s}^{-1}\right], E\left[3.56 \mu \mathrm{mol}\left(\mathrm{H}_{2} \mathrm{O}\right)\right.$ $\left.\mathrm{m}^{-2} \mathrm{~s}^{-1}\right], g_{\mathrm{s}}\left(0.17 \mathrm{mmol} \mathrm{m}^{-2} \mathrm{~s}^{-1}\right)$, and SPAD (43.33) were recorded in treatment LT1 of N12 while minimum values for $P_{\mathrm{N}}\left[3.7 \mu \mathrm{mol}\left(\mathrm{CO}_{2}\right) \mathrm{m}^{-2} \mathrm{~s}^{-1}\right], E\left[1.1 \mu \mathrm{mol}\left(\mathrm{H}_{2} \mathrm{O}\right) \mathrm{m}^{-2} \mathrm{~s}^{-1}\right]$, $g_{\mathrm{s}}\left(0.02 \mathrm{mmol} \mathrm{m}^{-2} \mathrm{~s}^{-1}\right)$, and SPAD (29.59) were recorded in treatment LT3 of C103. Our results demonstrated that under increasing drought stress conditions, the shade environment led to better photosynthetic performance (i.e., under treatment $\mathrm{T} 2$ in $\mathrm{N} 12$ and treatment $\mathrm{T} 3$ in $\mathrm{C} 103$ ) by improving $E, g_{\mathrm{s}}$, and SPAD values.

Chl fluorescence parameters: Increasing the severity of moisture stress significantly reduced the efficacy of photochemical machinery of both soybean cultivars 

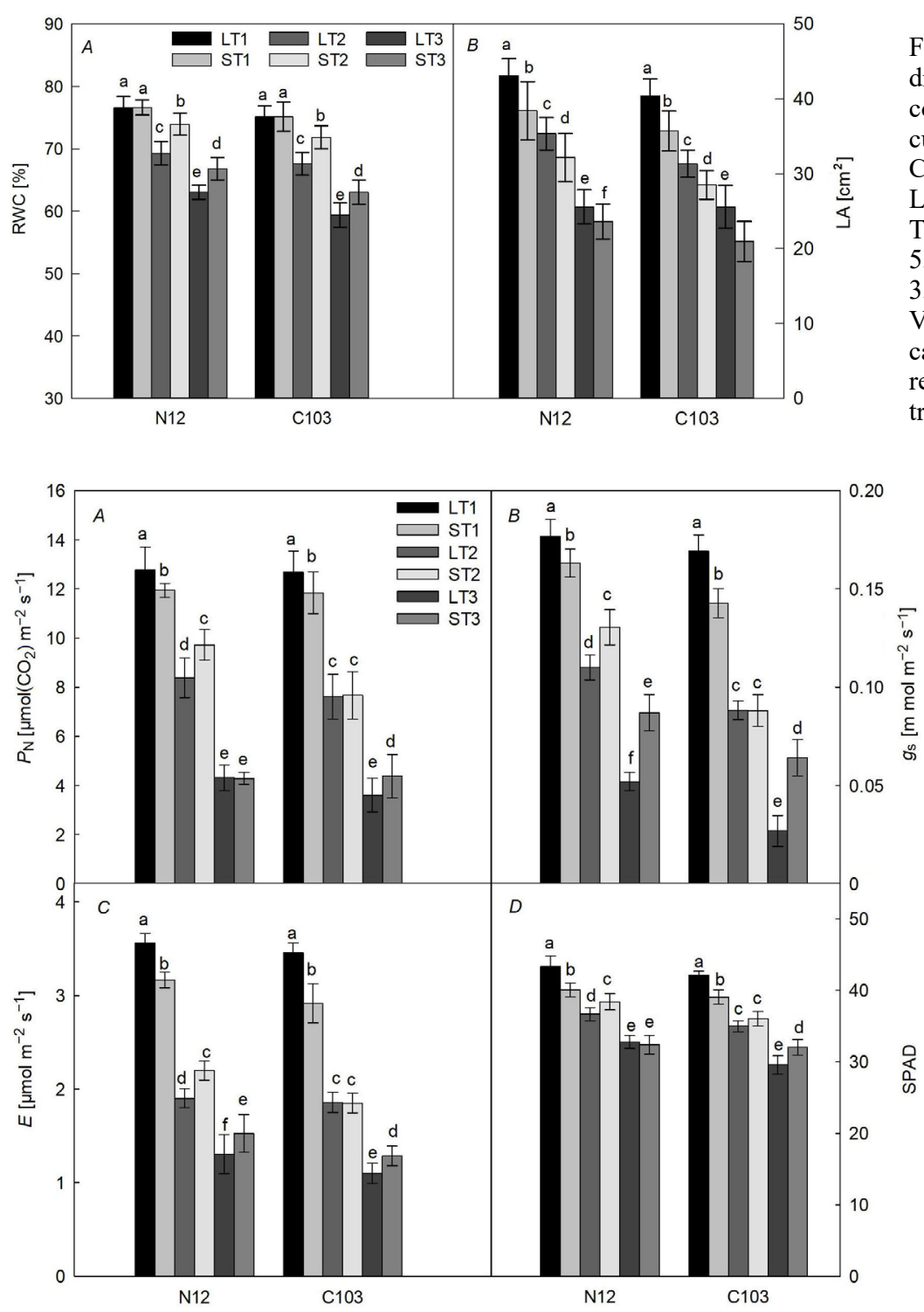

Fig. 2. The effect of different light regimes and drought stress treatments on $(A)$ relative water content RWC and $(B)$ leaf area (LA) of two soybean cultivars, N12 (shade- and drought-resistant) and C103 (shade- and drought-susceptible), respectively. $\mathrm{L}$ and $\mathrm{S}$ refer to full light and shade, respectively. T1, $\mathrm{T} 2$, and $\mathrm{T} 3$ refer to $75 \pm 2 \%$ field capacity (control), $55 \pm 2 \%$ field capacity (moderate drought), and $35 \pm 2 \%$ field capacity (severe drought), respectively. Values are the mean of three replicates. Bars indicate \pm SD. Different lowercase letters above the bars represent a significant difference $(P<0.05)$ between treatments.

Fig. 3. The effect of different light regimes and drought stress treatments on $(A)$ net photosynthesis $\left(P_{\mathrm{N}}\right),(B)$ stomatal conductance $\left(g_{\mathrm{s}}\right)$, (C) transpiration rate $(E)$, and $(D)$ SPAD value of two soybean cultivars, N12 (shadeand drought-resistant) and C103 (shade- and drought-susceptible), respectively. $\mathrm{L}$ and $\mathrm{S}$ refer to full light and shade, respectively. T1, $\mathrm{T} 2$, and $\mathrm{T} 3$ refer to $75 \pm 2 \%$ field capacity (control), $55 \pm 2 \%$ field capacity (moderate drought), and $35 \pm 2 \%$ field capacity (severe drought), respectively. Values are the mean of three replicates. Bars indicate \pm SD. Different lowercase letters above the bars represent a significant difference $(P<0.05)$ between treatments.

indicating that changes in photosynthetic rate under increasing moisture stress were directly associated with the changes in Chl fluorescence parameters (Fig. 4). The maximum quantum yield $\left(\mathrm{F}_{\mathrm{v}} / \mathrm{F}_{\mathrm{m}}\right)$, effective quantum yield of PSII ( $\left.\Phi_{\text {PSII }}\right)$, photochemical quenching $\left(\mathrm{q}_{\mathrm{P}}\right)$, and electron transport rate (ETR) decreased significantly with increasing severity of drought stress under both light regimes in both cultivars, however, the decrease was significantly higher in $\mathrm{C} 103$ in comparison to N12. In comparison to full light, the shade environment significantly improved $F_{v} / F_{m}$, $\Phi_{\text {PSII }}, \mathrm{q}_{\mathrm{P}}$, and ETR in T2 by $2.5,3.5,2.0$, and $5.2 \%$ in $\mathrm{N} 12$ and in $\mathrm{T} 3$ by $3,3.7,4.7$, and $3.7 \%$ in $\mathrm{C} 103$, respectively. The maximum values of $F_{\mathrm{v}} / \mathrm{F}_{\mathrm{m}}(0.804)$, $\Phi_{\text {PSII }}(0.243), \mathrm{q}_{\mathrm{P}}$ (0.450), and ETR (103.3) were observed in N12 in T1 under full light while minimum values of $\mathrm{F}_{\mathrm{v}} / \mathrm{F}_{\mathrm{m}}(0.707)$, $\Phi_{\text {PSII }}(0.201), \mathrm{q}_{\mathrm{P}}(0.390)$, and ETR (85.595) were found in $\mathrm{C} 103$ in $\mathrm{T} 3$ under normal light conditions, respectively. The interaction of light environment and drought stress was found to be highly significant for all the recorded photochemical parameters.
Rubisco activity: The Rubisco activity (RA) of both soybean cultivars decreased significantly as the drought stress intensified, the decrease being significantly higher in C103 in comparison to N12 (Fig. 5). The maximum $\left(0.281 \mathrm{U} \mathrm{g} \mathrm{g}^{-1}\right)$ and minimum $\left(0.173 \mathrm{U} \mathrm{g} \mathrm{g}^{-1}\right)$ values of RA were recorded in T1 and T3 in N12 and C103, respectively, under full light conditions. In comparison to full light, the shade environment played a positive role by significantly improving the Rubisco activity in treatment T2 in N12 and treatment $\mathrm{T} 3$ in $\mathrm{C} 103$, respectively. The RA increased by 6.8 and $3.7 \%$ and 0.5 and $6.2 \%$ in $\mathrm{T} 2$ and $\mathrm{T} 3$ in N12 and C103, respectively, under the shade environment. Overall, the interactive effect of light environment and the drought stress on RA was found to be highly significant.

Yield parameters: Increasing the severity of drought stress resulted in a significant reduction of the seed yield per plant, 100-seed mass, number of grains per plant, and the number of pods per plant in both cultivars (Fig. 6). However, shade significantly enhanced the seed yield, 


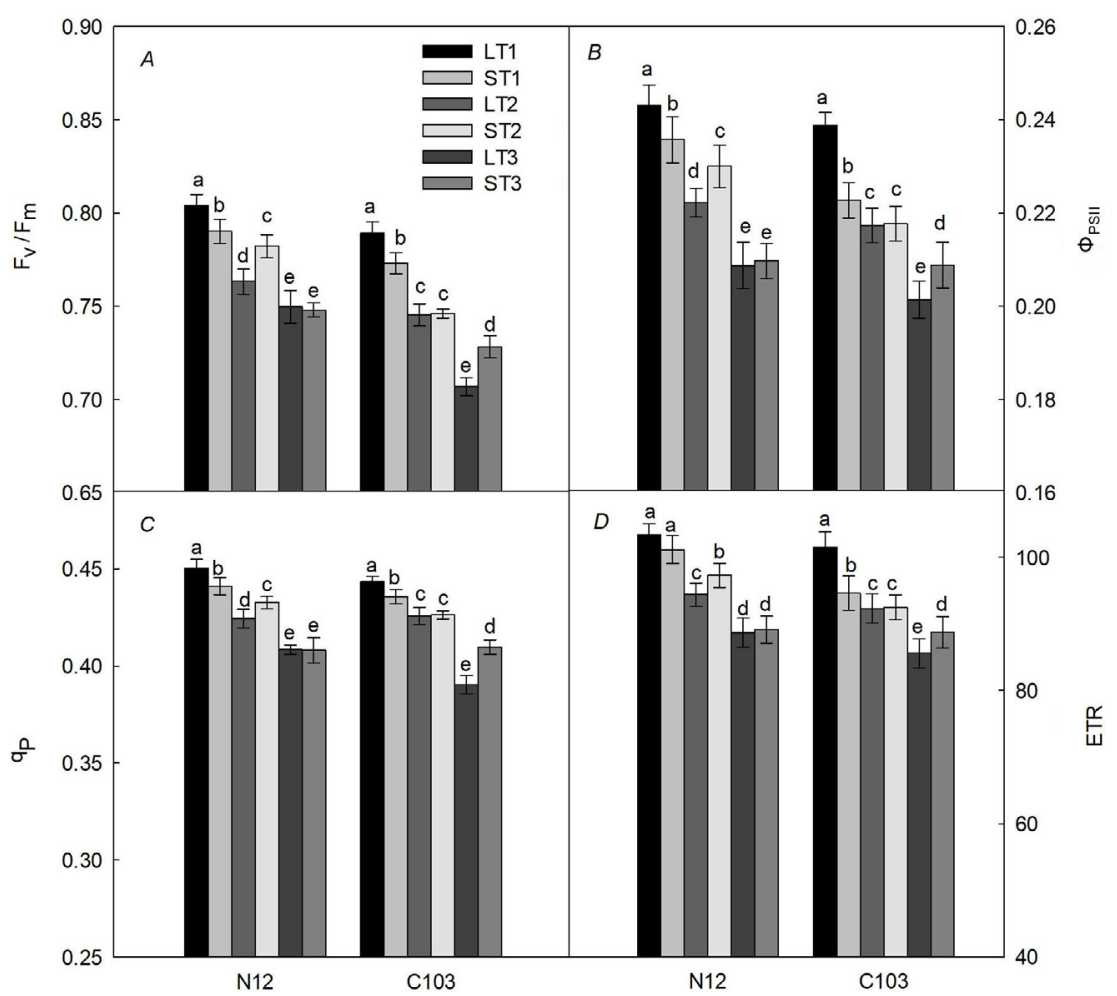

Fig. 4. The effect of different light regimes and drought stress treatments on $(A)$ maximum quantum yield $\left(\mathrm{F}_{\mathrm{v}} / \mathrm{F}_{\mathrm{m}}\right)$, $(B)$ effective quantum yield of PSII $\left(\Phi_{\mathrm{PSII}}\right),(C)$ photochemical quenching $\left(\mathrm{q}_{\mathrm{P}}\right)$, and $(D)$ electron transport rate (ETR) of two soybean cultivars, N12 (shade- and drought-resistant) and C103 (shade- and drought-susceptible), respectively. L and $\mathrm{S}$ refer to full light and shade, respectively. $\mathrm{T} 1, \mathrm{~T} 2$, and $\mathrm{T} 3$ refer to $75 \pm 2 \%$ field capacity (control), $55 \pm 2 \%$ field capacity (moderate drought), and $35 \pm$ $2 \%$ field capacity (severe drought), respectively. Values are the mean of three replicates. Bars indicate \pm SD. Different lowercase letters above the bars represent a significant difference $(P<0.05)$ between treatments.

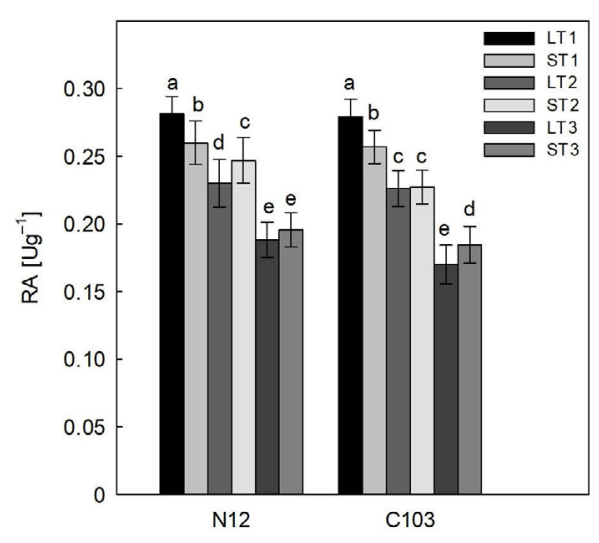

Fig. 5. The effect of different light regimes and drought stress treatments on Rubisco activity (RA) of two soybean cultivars, N12 (shade- and drought-resistant) and C103 (shade- and drought-susceptible), respectively. $\mathrm{L}$ and $\mathrm{S}$ refer to full light and shade, respectively. T1, T2, and T3 refer to $75 \pm 2 \%$ field capacity (control), $55 \pm 2 \%$ field capacity (moderate drought), and $35 \pm 2 \%$ field capacity (severe drought), respectively. Values are the mean of three replicates. Bars indicate \pm SD. Different lowercase letters above the bars represent a significant difference $(P<0.05)$ between treatments.

100 -seed mass, number of grains per plant, number of pods per plant in T2 and T3 by $6.9,4.8,10.6,14.8 \%$ and by $15.1,6.4,9.3,10.5 \%$ in N12 and C103, respectively. The maximum values for seed yield per plant (24.11 g), 100 -seed mass (17.63 g), number of grains per plant (147.6), and number of pods per plant (53.6) were recorded in treatment LT1 of N12 while minimum values for seed yield per plant (11 g), 100-seed mass (14.02 g), number of grains per plant (92.3), and number of pods per plant (25.3) were recorded in treatment LT3 of C103. The number of infertile pods increased significantly with increasing levels of drought stress under full light conditions in both cultivars. However, shade resulted in a significant reduction in the number of infertile pods in treatment $\mathrm{T} 2$ of $\mathrm{N} 12$ (by $33.0 \%$ ) and in T3 of C103 (by $10.3 \%$ ), respectively. The maximum number of infertile pods (14.3) were recorded in treatment LT3 of C103 while minimum value (3.0) was recorded in treatment LT1 of N12, respectively.

\section{Discussion}

In the present study, both shade and drought stress limited the growth of soybean cultivars. Increasing the severity of drought stress resulted in a reduction of biomass production in both soybean cultivars which is also supported by earlier research (Du et al. 2020). The plant height decreased under drought conditions whereas shade led to a slender stem and increased plant height with the increase being greater in C103 in comparison to N12 which shows that the tolerant variety exhibited less shade avoidance and was not prone to lodging (Wu et al. 2017, Hussain et al. 2020b).

Leaf area is considered to be an important factor that affects the light interception in plants and biomass production (Yao et al. 2016). Reduction in leaf area under shade and drought was observed as a strategy of plants to reduce water loss under conditions of water scarcity and is consistent with earlier research (Dong et al. 2019). This reduction probably leads to the reduction in the soybean biomass accumulation which has been confirmed 


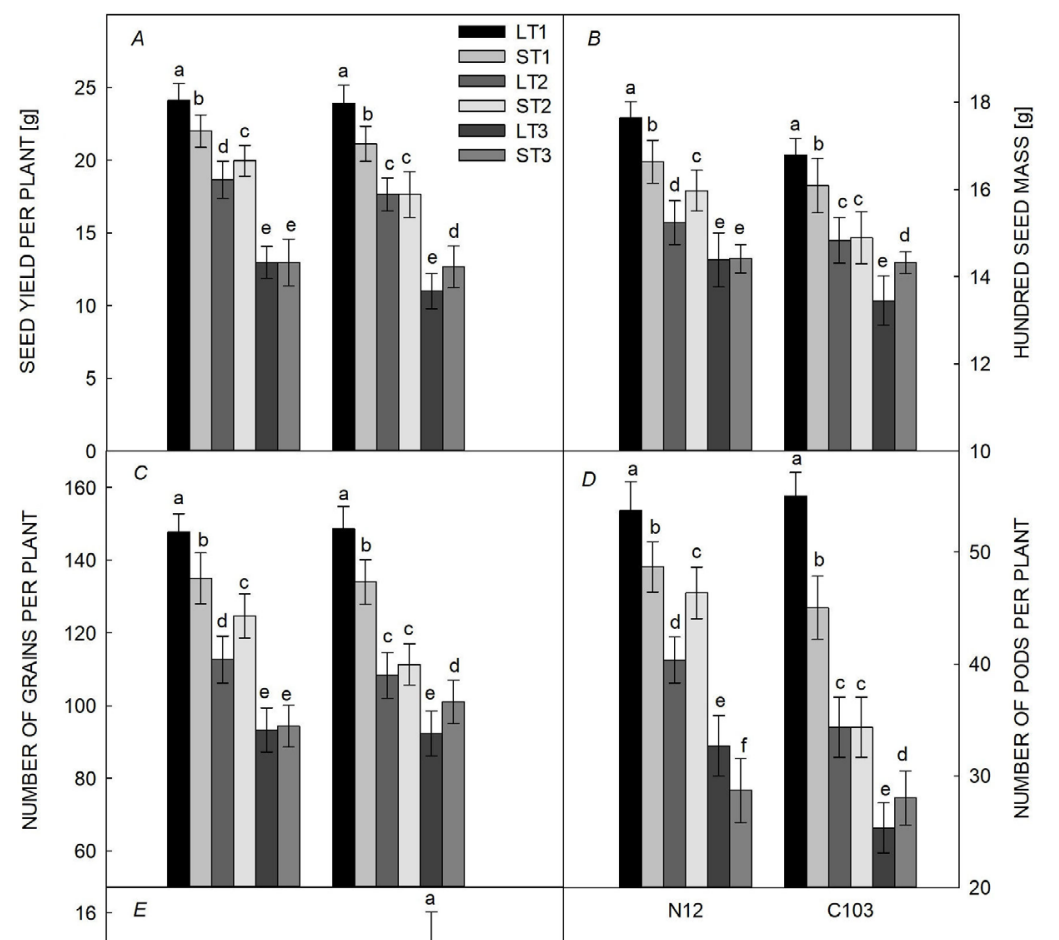

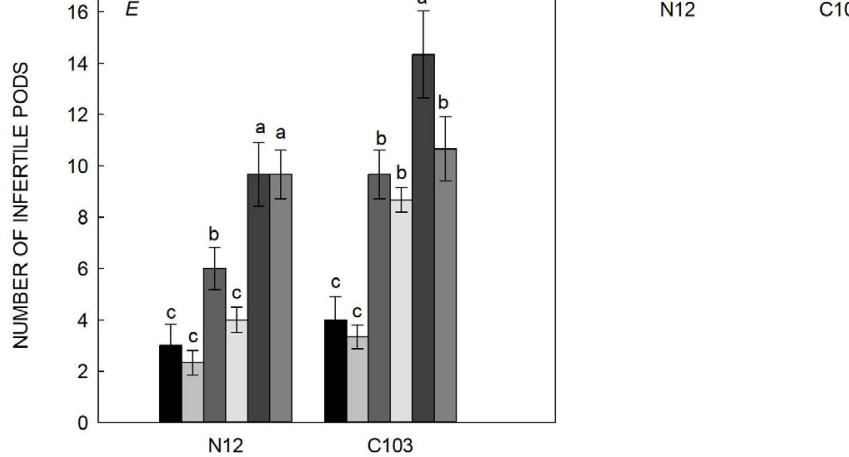

earlier by Su et al. (2014) and Wang et al. (2014). The relative water content (RWC) was also regressively reduced with increasing drought stress while higher RWC values observed under shade may be attributed to higher relative humidity and lower temperature under a shaded environment. The shaded plants need less water in comparison to those grown under full light as they can conserve water and require less water for transpiration (Holmgren 2000, Li et al. 2011).

Plants alter their photosynthetic characteristics to acclimate to various environmental conditions (Hussain et al. 2020c). Drought stress is reported to negatively affect the leaf gas-exchange parameters under full light as well as shade conditions (Chaves et al. 2009, Duan et al. 2009, Li et al. 2011). Our study was also consistent with these findings, the decrease in $P_{\mathrm{N}}$ was attributed to the decrease in $g_{\text {s }}$ and $E$. The decrease was greater for $\mathrm{C} 103$ in comparison to N12 which proves the high drought resistance of N12 (Iqbal et al. 2019). However, in comparison to full light, under shade conditions, $P_{\mathrm{N}}$ increased significantly which depicts a positive role of shade under drought conditions and supports the facilitation hypothesis (Holmgren 2000, Quero et al. 2006). Moreover, the reduction ratio for all
Fig. 6. The effect of different light regimes and drought stress treatments on $(A)$ seed yield per plant, $(B) 100$-seed mass, $(C)$ the number of grains per plant, $(D)$ the number of pods per plant, and $(E)$ the number of infertile pods of two soybean cultivars, N12 (shade- and drought-resistant) and $\mathrm{C} 103$ (shade- and droughtsusceptible), respectively. $\mathrm{L}$ and $\mathrm{S}$ refer to full light and shade, respectively. $\mathrm{T} 1, \mathrm{~T} 2$, and $\mathrm{T} 3$ refer to $75 \pm 2 \%$ field capacity (control), $55 \pm 2 \%$ field capacity (moderate drought), and $35 \pm$ $2 \%$ field capacity (severe drought), respectively. Values are the mean of three replicates. Bars indicate \pm SD. Different lowercase letters above the bars represent a significant difference $(P<0.05)$ between treatments.

the measured gas-exchange parameters was lesser in the shade environment as compared to full light. Besides, the SPAD value also decreased in both cultivars as the level of drought intensified (Gunes et al. 2008) but the reduction was greater under full light in comparison to the shade environment. Also, the SPAD values for N12 were greater in comparison to $\mathrm{C} 103$ which probably contributed to the better photosynthetic performance of the former cultivar.

In our present study, as the severity of drought stress increased, $\mathrm{F}_{\mathrm{v}} / \mathrm{F}_{\mathrm{m}}, \mathrm{q}_{\mathrm{P}}, \Phi_{\mathrm{PSII}}$, and ETR decreased significantly under both light regimes which is consistent with the earlier reported research (Hussain et al. 2019c, Iqbal et al. 2019). The decrease was recorded to be greater in plants grown under full light as compared to those grown under shade conditions. Moreover, the decrease in Chl fluorescence parameters was greater in $\mathrm{C} 103$ in comparison to $\mathrm{N} 12$ which suggests that the structural integrity of PSII of N12 was not damaged by stress conditions. N12 proved to be a resistant cultivar with better photosynthetic performance and agricultural productivity.

A rapid decrease in RA is a prominent plant response against drought stress (Parry et al. 2002). In our study, RA decreased under both light regimes as the severity of 
drought stress increased. This is consistent with earlier reported literature (Majumdar et al. 1991, Bota et al. 2004). The reduced RA contributed to the reduction of photosynthetic performance as Rubisco plays an important role in the biochemical limitation of photosynthesis in plants under water deficit (Perdomo et al. 2017). Interestingly, in comparison to full light, RA increased under shade conditions, which is why comparatively better $P_{\mathrm{N}}$ values were obtained under shade environment than under full light conditions.

Drought and shade stresses are the prime abiotic constraints that substantially affect the seed yield by reducing the pod and seed number, eventually affecting the commercial trait ' 100 -seed mass'. In our study, the seed yield of both cultivars decreased significantly as the severity of drought stress increased. This is in line with the earlier research (Desclaux et al. 2000, Liu et al. 2003, Stolf-Moreira et al. 2010, Iqbal et al. 2018). However, the results of our study demonstrated a significantly higher seed yield of N12 (under moderate drought stress) and C103 (under severe drought stress) under shade conditions as compared to full light. This indicates a better performance of soybean plants exposed to drought stress under shade which shows that a moderate shade can help soybean to mitigate the drought stress. Overall, N12 showed better yield production in comparison to $\mathrm{C} 103$ which proves its resistance to shade and drought stress.

Conclusion: Our research demonstrated that increasing the level of drought stress resulted in the poor photosynthetic performance of soybean cultivars due to reduction in leaf area, relative water content, leaf gas-exchange parameters (i.e., $P_{\mathrm{N}}, E$, and $g_{\mathrm{s}}$ ), chlorophyll fluorescence parameters (i.e., $\mathrm{F}_{\mathrm{v}} / \mathrm{F}_{\mathrm{m}}, \Phi_{\mathrm{PSII}}, \mathrm{q}_{\mathrm{P}}$, and ETR), chlorophyll content, and Rubisco activity which ultimately led to yield reduction. In conclusion, with the appropriate selection of cultivars, a moderate shade can help to optimize yield and improve the performance of soybean exposed to drought stress in maize-soybean relay intercropping system. However, further research considering the effect of different shade levels on soybean performance under drought conditions is required under field conditions. It is obvious that under field conditions, in the presence of maize, the effects of inter- and intraspecific competition can play an important role in altering the growth, photosynthesis, and drought tolerance of soybean. Therefore, further research in this direction, when considering the above-mentioned facts, can provide a better insight into the role of shade in the alleviation of drought stress in soybean under maizesoybean relay intercropping system.

\section{References}

Aranda I., Castro L., Pardos M. et al.: Effects of the interaction between drought and shade on water relations, gas exchange and morphological traits in cork oak (Quercus suber L.) seedlings. - Forest Ecol. Manag. 210: 117-129, 2005.

Ashraf M., Harris P.J.C.: Photosynthesis under stressful environments: An overview. - Photosynthetica 51: 163-190, 2013.

Basu S., Ramegowda V., Kumar A., Pereira A.: Plant adaptation to drought stress. - F1000Res. 5: 1554, 2016.

Bota J., Medrano H., Flexas J.: Is photosynthesis limited by decreased Rubisco activity and RuBP content under progressive water stress? - New Phytol. 162: 671-681, 2004.

Chaves M.M., Flexas J., Pinheiro C.: Photosynthesis under drought and salt stress: regulation mechanisms from whole plant to cell. - Ann. Bot.-London 103: 551-560, 2009.

Dai Y., Shen Z., Liu Y. et al.: Effects of shade treatments on the photosynthetic capacity, chlorophyll fluorescence, and chlorophyll content of Tetrastigma hemsleyanum Diels et Gilg. - Environ. Exp. Bot. 65: 177-182, 2009.

Desclaux D., Huynh T.T., Roumet P.: Identification of soybean plant characteristics that indicate the timing of drought stress. Crop Sci. 40: 716-722, 2000.

Dong S., Jiang Y., Dong Y. et al.: A study on soybean responses to drought stress and rehydration. - Saudi J. Biol. Sci. 26: 2006-2017, 2019.

Du Y., Zhao Q., Chen L. et al.: Effect of drought stress on sugar metabolism in leaves and roots of soybean seedlings. - Plant Physiol. Bioch. 146: 1-12, 2020.

Duan B., Li Y., Zhang X. et al.: Water deficit affects mesophyll limitation of leaves more strongly in sun than in shade in two contrasting Picea asperata populations. - Tree Physiol. 29: 1551-1561, 2009.

Estill K., Delaney R.H., Smith W.K., Ditterline R.L.: Water relations and productivity of alfalfa leaf chlorophyll variants. - Crop Sci. 31: 1229-1233, 1991.

Faijunnahar M., Baque A., Habib M.A., Hossain H.M.M.T.: Polyethylene glycol (PEG) induced changes in germination, seedling growth and water relation behavior of wheat (Triticum aestivum L.) genotypes. - Univers. J. Plant Sci. 5: 49-57, 2017.

Feng L., Raza M.A., Chen Y. et al.: Narrow-wide row planting pattern improves the light environment and seed yields of intercrop species in relay intercropping system. - PLoS ONE 14: e0212885, 2019.

Galmés J., Ribas-Carbó M., Medrano H., Flexas J.: Rubisco activity in Mediterranean species is regulated by the chloroplastic $\mathrm{CO}_{2}$ concentration under water stress. - J. Exp. Bot. 62: 653-665, 2011.

Gregoriou K., Pontikis K., Vemmos S.: Effects of reduced irradiance on leaf morphology, photosynthetic capacity, and fruit yield in olive (Olea europaea L.). - Photosynthetica 45: 172-181, 2007.

Gunes A., Inal A., Adak M. et al.: Effect of drought stress implemented at pre- or post-anthesis stage on some physiological parameters as screening criteria in chickpea cultivars. - Russ J. Plant Physl+ 55: 59-67, 2008.

Hamada A.M., Al-Hakimi A.N.: Salicylic acid versus salinitydrought-induced stress on wheat seedlings. - Rostlinná výroba 47: 444-450, 2001.

Holmgren M.: Combined effects of shade and drought on tulip poplar seedlings: trade-off in tolerance or facilitation? - Oikos 90: $67-78,2000$.

Huang W., Zhang S.B., Liu T.: Moderate photoinhibition of photosystem II significantly affects linear electron flow in the shade-demanding plant Panax notoginseng. - Front. Plant Sci. 9: 637, 2018.

Hussain S., Iqbal N., Brestic M. et al.: Changes in morphology, chlorophyll fluorescence performance and Rubisco activity of soybean in response to foliar application of ionic titanium under normal light and shade environment. - Sci. Total Environ. 658: 626-637, 2019b.

Hussain S., Iqbal N., Rahman T. et al.: Shade effect on carbohydrates dynamics and stem strength of soybean genotypes. - Environ. Exp. Bot. 162: 374-382, 2019a. 
Hussain S., Iqbal N., Raza M.A. et al.: Distribution and effects of ionic titanium application on energy partitioning and quantum yield of soybean under different light conditions. Photosynthetica 57: 572-580, 2019c.

Hussain S., Liu T., Iqbal N. et al.: Effects of lignin, cellulose, hemicellulose, sucrose and monosaccharide carbohydrates on soybean physical stem strength and yield in intercropping. Photoch. Photobio. Sci. 19: 462-472, 2020 b.

Hussain S., Pang T., Iqbal N. et al.: Acclimation strategy and plasticity of different soybean genotypes in intercropping. Funct. Plant Biol. 47: 592-610, 2020c.

Hussain S., Shuxian L., Mumtaz M. et al.: Foliar application of silicon improves stem strength under low light stress by regulating lignin biosynthesis genes in soybean (Glycine max (L.) Merr.). - J. Hazard. Mater. 401: 123256, 2020a.

Iqbal N., Hussain S., Raza M.A. et al:: Drought tolerance of soybean (Glycine max L. Merr.) by improved photosynthetic characteristics and an efficient antioxidant enzyme system under a split-root system. - Front. Physiol. 10: 786, 2019.

Iqbal N., Hussain S., Zhang X.W. et al.: Imbalance water deficit improves the seed yield and quality of soybean. - Agronomy 8: $168,2018$.

Karam F., Masaad R., Sfeir T. et al.: Evapotranspiration and seed yield of field grown soybean under deficit irrigation conditions. - Agr. Water Manage. 75: 226-244, 2005.

Komura M., Yamagishi A., Shibata Y. et al.: Mechanism of strong quenching of photosystem II chlorophyll fluorescence under drought stress in a lichen, Physciella melanchla, studied by subpicosecond fluorescence spectroscopy. - BBABioenergetics 1797: 331-338, 2010.

Li Y., Zhao H., Duan B. et al.: Effect of drought and ABA on growth, photosynthesis and antioxidant system of Cotinus coggygria seedlings under two different light conditions. Environ. Exp. Bot. 71: 107-113, 2011.

Lichtenthaler H.K., Ač A., Marek M.V. et al.: Differences in pigment composition, photosynthetic rates and chlorophyll fluorescence images of sun and shade leaves of four tree species. - Plant Physiol. Bioch. 45: 577-588, 2007.

Liu F., Andersen M.N., Jensen C.R.: Loss of pod set caused by drought stress is associated with water status and $\mathrm{ABA}$ content of reproductive structures in soybean. - Funct. Plant Biol. 30: 271-280, 2003

Majumdar S., Ghosh S., Glick B.R., Dumbroff E.B.: Activities of chlorophyllase, phosphoenolpyruvate carboxylase and ribulose-1,5-bisphosphate carboxylase in the primary leaves of soybean during senescence and drought. - Physiol. Plantarum 81: 473-480, 1991.

Manivannan P., Jaleel C.A., Sankar B. et al.: Growth, biochemical modifications and proline metabolism in Helianthus annuus L. as induced by drought stress. - Colloid. Surface B 59: 141149, 2007.

Masoumi H., Darvish F., Daneshian J. et al.: Effects of water deficit stress on seed yield and antioxidants content in soybean (Glycine max L.) cultivars. - Afr. J. Agr. Res. 6: 1209-1218, 2011.

Melgar J.C., Guidi L., Remorini D. et al.: Antioxidant defences and oxidative damage in salt-treated olive plants under contrasting sunlight irradiance. - Tree Physiol. 29: 11871198, 2009.

Murchie E.H., Lawson T.: Chlorophyll fluorescence analysis: a guide to good practice and understanding some new applications. - J. Exp. Bot. 64: 3983-3998, 2013.

Ommen O.E., Donnelly A., Vanhoutvin S. et al.: Chlorophyll content of spring wheat flag leaves grown under elevated $\mathrm{CO}_{2}$ concentrations and other environmental stresses within the 'ESPACE-wheat' project. - Eur. J. Agron. 10: 197-203, 1999.
Parry M.A., Andralojc P.J., Khan S. et al.: Rubisco activity: effects of drought stress. - Ann. Bot.-London 89: 833-839, 2002.

Perdomo J.A., Capó-Bauçà S., Carmo-Silva E., Galmés J.: Rubisco and rubisco activase play an important role in the biochemical limitations of photosynthesis in rice, wheat, and maize under high temperature and water deficit. - Front. Plant Sci. 8: 490, 2017.

Pirzad A., Shakiba M.R., Zehtab-Salmasi S. et al.: Effect of water stress on leaf relative water content, chlorophyll, proline and soluble carbohydrates in Matricaria chamomilla L. - J. Med. Plants Res. 5: 2483-2488, 2011.

Quero J.L., Villar R., Marañón T., Zamora R.: Interactions of drought and shade effects on seedlings of four Quercus species: physiological and structural leaf responses. - New Phytol. 170: 819-834, 2006.

Rahman T., Ye L., Liu X. et al.: Water use efficiency and water distribution response to different planting patterns in maizesoybean relay strip intercropping systems. - Exp. Agr. 53: 159-177, 2017.

Raza M.A., Feng L.Y., Iqbal N. et al.: Growth and development of soybean under changing light environments in relay intercropping system. - PeerJ 7: e7262, 2019.

Sack L.: Responses of temperate woody seedlings to shade and drought: do trade-offs limit potential niche differentiation? Oikos 107: 110-127, 2004.

Sack L., Grubb P.J.: The combined impacts of deep shade and drought on the growth and biomass allocation of shadetolerant woody seedlings. - Oecologia 131: 175-185, 2002.

Shafiq I., Hussain S., Muhammad A.R. et al.: Crop photosynthetic response to light quality and light intensity. - J. Integr. Agr. 19: 2-21, 2020.

Song L., Prince S., Valliyodan B. et al:: Genome-wide transcriptome analysis of soybean primary root under varying water-deficit conditions. - BMC Genomics 17: 57, 2016.

Stolf-Moreira R., Medri M., Neumaier N. et al.: Soybean physiology and gene expression during drought. - Genet. Mol. Res. 9: 1946-1956, 2010.

$\mathrm{Su}$ B., Song Y., Song C. et al.: Growth and photosynthetic responses of soybean seedlings to maize shading in relay intercropping system in Southwest China. - Photosynthetica 52: 332-340, 2014.

Sugiyama A.: The soybean rhizosphere: Metabolites, microbes, and beyond - A review. - J. Adv. Res. 19: 67-73, 2019.

Terashima I., Hanba Y.T., Tazoe Y. et al.: Irradiance and phenotype: comparative eco-development of sun and shade leaves in relation to photosynthetic $\mathrm{CO}_{2}$ diffusion. - J. Exp. Bot. 57: 343-354, 2006.

Tyczewska A., Woźniak E., Gracz J. et al.: Towards food security: current state and future prospects of agrobiotechnology. Trends Biotechnol. 36: 1219-1229, 2018.

Valladares F., Niinemets Ü.: Shade tolerance, a key plant feature of complex nature and consequences. - Annu. Rev. Ecol. Evol. Syst. 39: 237-257, 2008.

Wang N., Huang Q., Sun J. et al.: Shade tolerance plays an important role in biomass production of different poplar genotypes in a high-density plantation. - Forest Ecol. Manag. 331: 40-49, 2014.

Wu L., Zhang W., Ding Y. et al.: Shading contributes to the reduction of stem mechanical strength by decreasing cell wall synthesis in japonica rice (Oryza sativa L.). - Front. Plant Sci. 8: 881, 2017.

Yang F., Fan Y., Wu X. et al.: Auxin-to-gibberellin ratio as a signal for light intensity and quality in regulating soybean growth and matter partitioning. - Front. Plant Sci. 9: 56, 2018.

Yang F., Huang S., Gao R. et al.: Growth of soybean seedlings in 
relay strip intercropping systems in relation to light quantity and red: far-red ratio. - Field Crop. Res. 155: 245-253, 2014.

Yang F., Liao D., Wu X. et al.: Effect of aboveground and belowground interactions on the intercrop yields in maizesoybean relay intercropping systems. - Field Crop. Res. 203: 16-23, 2017.

Yao H., Zhang Y., Yi X. et al.: Cotton responds to different plant population densities by adjusting specific leaf area to optimize canopy photosynthetic use efficiency of light and nitrogen. Field Crop. Res. 188: 10-16, 2016.

Yao X., Li C., Li S. et al.: Effect of shade on leaf photosynthetic capacity, light-intercepting, electron transfer and energy distribution of soybeans. - Plant Growth Regul. 83: 409-416, 2017.
Zhou R., Kan X., Chen J. et al.: Drought-induced changes in photosynthetic electron transport in maize probed by prompt fluorescence, delayed fluorescence, P700 and cyclic electron flow signals. - Environ. Exp. Bot. 158: 51-62, 2019.

Zhu H., Li X., Zhai W. et al.: Effects of low light on photosynthetic properties, antioxidant enzyme activity, and anthocyanin accumulation in purple pak-choi (Brassica campestris ssp. Chinensis Makino). - PLoS ONE 12: e0179305, 2017.

Zivcak M., Brestic M., Kalaji H.M., Govindjee: Photosynthetic responses of sun-and shade-grown barley leaves to high light: is the lower PSII connectivity in shade leaves associated with protection against excess of light? - Photosynth. Res. 119: 339-354, 2014.

(C) The authors. This is an open access article distributed under the terms of the Creative Commons BY-NC-ND Licence. 